\title{
Reasons provided for requesting a termination of pregnancy in the UK
}

\author{
Tonye Telema Wokoma, ${ }^{1}$ Malathi Jampala, ${ }^{2}$ Helen Bexhell, ${ }^{3}$ \\ Kate A Guthrie, ${ }^{4}$ Stephen W Lindow ${ }^{5}$
}

\begin{abstract}
${ }^{1}$ Registrar, Sexual and Reproductive Healthcare, Conifer at Wilberforce Centre, Hull and Department of Obstetrics and Gynaecology, Hull Royal Infirmary, Hull and East Yorkshire NHS Trust, Hull, UK

${ }^{2} \mathrm{GP}$ Registrar, Lupset Surgery, Wakefield, UK

${ }^{3}$ Research Midwife, Hull Royal Infirmary, Hull and East Yorkshire NHS Trust, Hull, UK ${ }^{4}$ Consultant in Community Gynaecology, Sexual and Reproductive Healthcare, Conifer at Wilberforce Centre, Hull and Department of Obstetrics and Gynaecology, Hull Royal Infirmary, Hull and East Yorkshire NHS Trust, Hull, UK ${ }^{5}$ Consultant Obstetrician and Gynaecologist, Department of Obstetrics and Gynaecology, Hull York Medical School, Hull Royal Infirmary, Hull and East Yorkshire NHS Trust, Hull, UK
\end{abstract}

\section{Correspondence to Dr Tonye Wokoma, Sexual and Reproductive Healthcare, Conifer at Wilberforce Centre, 6-10 Story Street, Hull HU1 3SA, UK; tonye.wokoma@nhs.net}

Received 2 August 2013 Revised 20 March 2014 Accepted 9 April 2014 Published Online First 10 June 2014

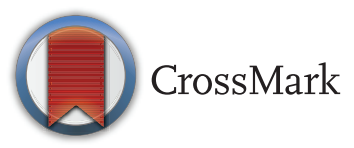

To cite: Wokoma TT, Jampala $\mathrm{M}$, Bexhell $\mathrm{H}$, et al. J Fam Plann Reprod Health Care 2015:41:186-192.

\begin{abstract}
Objective To determine the main reasons for termination of pregnancy (TOP) requests in a UK city.

Design A survey requesting reasons for a pregnancy termination from women attending a TOP clinic
\end{abstract}

Setting A TOP pre-assessment clinic in Hull and East Yorkshire Hospitals, UK.

Population A cohort of pregnant women requesting a TOP in the first trimester.

Methods A confidential, anonymous, self-administered questionnaire requesting demographic information about age, education, ethnicity and marital status. The questionnaire also asked for the main reasons underlying the TOP request. The main outcome measures were (1) reasons for TOP requests and (2) correlations between the reasons provided and demographic characteristics.

Results A total of 274 women participated in the study and 527 reasons were given. The most common reason was money worries (21.0\%) followed closely by contraception failure (20.5\%). The third most common reason was the anticipated effect on education or the woman's career $(14.6 \%)$ Over half $(59.5 \%)$ of the women were single and $8.8 \%$ were divorced or separated. Twenty-eight per cent of the respondents were aged 21 years and below, $36.1 \%$ were aged $22-29$ years and $29.2 \%$ were over 30 years of age.

Conclusions The main reasons for TOP requests included financial constraints, contraceptive failure, completion of family, and potential interruption of education or career. These reasons differed with age groups and marital status. Focused qualitative research on reasons for a TOP will provide further knowledge and understanding that is needed to enable optimal service provision and policy planning.

\section{INTRODUCTION}

In England and Wales, the total number of induced abortions in 2012 was 185 122, representing an increase of $5.2 \%$ since

\section{Key message points}

The main reasons for a termination of pregnancy (TOP) request include financial constraints, contraceptive failure, completion of family, and interruption of education or career.

- Contraceptive failure was noted to be a significant reason given by women in all age groups.

- Research is needed to find ways of addressing the reasons given for requesting TOPs with a view to reducing the need for this intervention.

2002. With the growing number of women seeking a termination of pregnancy (TOP) in the last decade, it is imperative to understand the underlying reasons behind these requests. However, these reasons are often difficult to ascertain, as it requires women to articulate the often complex and sensitive process that led to their decision making. ${ }^{2}$ Nevertheless, further knowledge and understanding would be useful in planning services, informing strategic policies and improving the general standard of care. The information gathered during the process can also be used to enlighten the public with a view to changing attitudes arising through misperceptions. ${ }^{3}$

Several studies have previously tried to elucidate the reasons for a TOP request, with the consensus being that these reasons are rarely solitary. ${ }^{2-4}$ They are often complex and interrelated, ${ }^{5}$ with women often expressing both ambivalence and feelings of uncertainty about their decision. ${ }^{4}$ However, the choice was made to proceed with a TOP because continuing with the pregnancy was assessed as having short- and long-term adverse effects on the woman and significant others. ${ }^{5}$ 
Though a high proportion of women become pregnant unintentionally, both in developed and resourcepoor countries, for others the pregnancy was intended but the circumstances then changed. ${ }^{2}$ A UK study showed that teenage pregnancies are usually not planned, and consequently half the pregnancies in under-18s are aborted. ${ }^{6}$ Some women have reported that their pregnancies resulted from coerced sexual intercourse when they had not used contraceptives. ${ }^{7}$ A TOP request is often linked to social and demographic characteristics. ${ }^{3}$ In the USA, the demographic characteristics of women requesting a TOP are known to have altered since 1987, with a higher probability of TOP observed in women with one or more children, poor women and those aged 30 years or older. $^{3} 9$

Common reasons for a TOP request include contraceptive failure, inappropriate timing or planning, broken or disruptive relationships with partners, financial status or low income, and moral and cultural factors. ${ }^{3} 910$

Many terms are currently in use for induced abortion. This article uses the term TOP.

This study examined the reasons provided for a TOP request in a district general hospital setting in North East England. It explores the relationship between the reasons given and demographic factors such as age and marital status.

\section{METHODS}

Women attending a TOP pre-assessment clinic over a 2-year period in Hull Royal Infirmary in North East England were invited to participate in the study that investigated the prevalence of domestic violence (DV) in pregnant women in the first trimester attending antenatal and TOP clinics. As part of the research, the reasons for TOP requests were explored concurrently. The study received ethics committee approval from Yorkshire and Humber - Sheffield National Research Ethics Service and the local research ethics committee.

Data were collected by means of a confidential, anonymous, self-administered questionnaire. The responses were simple, easy to read and required participants to indicate a chosen option by ticking a box. The questionnaire was designed as a two-part exercise over two pages. The first part explored demographic characteristics such as age, marital status, ethnicity, education, number of children, previous terminations and information about ongoing relationships. The women were further asked to choose the main reasons for their TOP request. The reasons were to be ranked in order of importance. There were 10 response alternatives to the question on reasons for a TOP request; this large number was a deliberate attempt by investigators to capture the broad nature of the contributory factors to a woman's request for a
TOP. Women were asked to document the top three reasons for their request. Some participants also wrote down reasons other than the alternatives provided.

The second part of the questionnaire centred on relationship issues, questions on $\mathrm{DV}$, and whether the TOP request was known to the partner. Most of the questions in the questionnaire, particularly those relating to DV, had been used and validated in an earlier study ${ }^{11}$ but the questions on the reasons for TOP were devised by the authors specifically for the purpose of this study. The design and structure of the questions were discussed by members of the research team and piloted among a small number of women.

Inclusion criteria were all women over the age of 16 years seen in the TOP clinic during the study period. Women who required the services of an interpreter were excluded from the study because we believed that including them would be inappropriate and compromise confidentiality and anonymity.

The women were recruited into the study by nurses and health care assistants. A consulting room with a secure collection box was designated primarily for the purpose of the study.

At presentation to the TOP clinic, all the women were invited into the clinic room for routine height, weight and blood pressure measurements. At this time, the health care provider undertook an opportunistic recruitment of the patient into the study and verbal consent was obtained thereafter. Women accompanied by their partners or other third party to the clinic were invited to come in to the study room alone to have their measurements taken. Women who chose to come into the clinic room with their partners were excluded from participation. The investigators reasoned that the presence of another person might limit disclosure and have potential adverse consequences.

Information about the study was provided verbally to each participant by the recruiting health care provider. A laminated patient information leaflet was placed next to the collection box. This could not be removed from the designated study room on the basis that it contained questions of a sensitive nature that could potentially exacerbate an already difficult situation.

Consenting participants were allowed privacy to complete the questionnaire and were instructed to place the completed questionnaire in the collection box. Participants were under no obligation to complete all the questions. Helpline numbers were provided at the end of each questionnaire and necessary support for the women was provided as required according to routine clinic practice.

Anonymised data were entered into an Excel spreadsheet; the software used for the data analysis was SPSS (SPSS V.19.0; IBM, Chicago, IL, USA). The descriptive statistics were calculated using percentages and variables compared using Chi-square $\left(\chi^{2}\right)$ tests. 


\section{RESULTS}

A total of 274 women were recruited for the study in the TOP clinic from January 2011 to November 2012. The total clinic attendance for the same period was 3155 women. Demographic characteristics of the study participants are summarised in Table 1.

The most common reason given by the women requesting a TOP was money worries $(21.0 \%)$ followed closely by failure of contraception (20.5\%). The third most common reason was the anticipated effect on education or career (14.6\%). These three reasons also occurred in combination in 10\% (26 women) of all responders although prioritisation was different. The reasons for a TOP request are shown in Table 2.

Other than the 10 alternative reasons provided, eight respondents provided free-text options. These included maternal health, age of mother ('too old'), respondent had just had a baby, and respondent did not feel ready for another pregnancy.

While multiple reasons were provided by 162 women (59.1\%), 17 women (6.2\%) gave no reason for their TOP request. Consequently, 527 reasons were documented in this study with 96 women

Table 1 Characteristics of women requesting a termination of pregnancy $(n=274)$

\begin{tabular}{|c|c|c|}
\hline Characteristic & $n$ & $\%$ \\
\hline \multicolumn{3}{|l|}{ Age (years) } \\
\hline$\leq 21$ & 77 & 28.1 \\
\hline $22-29$ & 99 & 36.1 \\
\hline$>30$ & 80 & 29.1 \\
\hline Not answered & 18 & 6.6 \\
\hline \multicolumn{3}{|l|}{ Marital status } \\
\hline Single & 163 & 59.5 \\
\hline Married/cohabiting & 79 & 28.8 \\
\hline Divorced/separated & 24 & 8.8 \\
\hline Not answered & 8 & 2.9 \\
\hline \multicolumn{3}{|l|}{ Ethnicity } \\
\hline White & 256 & 93.4 \\
\hline Black & 4 & 1.5 \\
\hline Asian & 6 & 2.2 \\
\hline Mixed & 8 & 2.9 \\
\hline Not answered & 0 & 0.0 \\
\hline \multicolumn{3}{|l|}{ Education } \\
\hline GCSE & 125 & 45.6 \\
\hline A-level & 45 & 16.4 \\
\hline Degree (Bachelor's) & 30 & 10.9 \\
\hline Other higher education & 34 & 12.4 \\
\hline None & 1 & 0.4 \\
\hline Not answered & 39 & 14.2 \\
\hline \multicolumn{3}{|l|}{ In a relationship } \\
\hline Yes & 181 & 66.1 \\
\hline No & 92 & 33.6 \\
\hline Not answered & 1 & 0.4 \\
\hline
\end{tabular}

GCSE, General Certificate of Secondary Education.
(35.1\%) giving one reason, 55 women $(20.1 \%)$ two reasons and 107 women (39.1\%) three reasons. If more than three reasons were provided, only the first three were considered in the analysis.

Women who had had a previous TOP were more likely to offer a solitary reason for their request $(p=0.016)$. Women with educational status above Advanced level (A-level) certification appeared more likely to offer multiple reasons for their request (46/ $64 ; 72 \%)$ than women with A-level qualifications or below $(97 / 171 ; 57 \%)$, however this did not reach statistical significance $(p=0.129)$. There was no significant difference in the number of reasons provided based on whether the woman was in a relationship $(p=0.431)$. Women who reported 'violent relationship' and 'family complete' mostly provided this as the only reason for their request although the numbers are small (Table 2).

The mean age at TOP was 24 years. Reasons for TOP requests differed significantly by age (Table 3 ). Older women ( $\geq 30$ years) were less likely to report money worries as a reason for a TOP request $(p=0.001)$. Younger women ( $\leq 30$ years) were more likely to cite interruption of education or career $(p=0.021)$. Contraceptive failure was common to all age groups, however the difference between the age groups was not statistically significant $(p=0.241)$.

Over half $(59.5 \%)$ of the respondents were single and $8.8 \%$ were divorced or separated. One-third $(28.8 \%)$ were married or co-habiting. The most common reason given by single women for a TOP request was 'money worries' (69/328; 21.0\%). 'Money worries' was the second most common reason reported for married women. There was no significant difference between single and married women regarding the choice of money worries as a reason for a TOP request $(p=0.625)$. For married women, contraceptive failure was the main reason given (38/135; $16.2 \%)$, while for the divorced/separated category completion of family was the main reason cited (10/ $49 ; 20.4 \%)$. There was no correlation between the choice of contraceptive failure as a reason for TOP and the marital status of the responder $(p=0.144)$ (Table 4).

Educational status appeared to have an influence on the reasons given for a TOP request (Table 5). Forty-six percent of the women had attained the General Certificate of Secondary Education (GCSE), while 16.4\% had A-levels and 23.3\% had a Bachelor's degree or some form of higher education. Women with a Bachelor's degree were more likely to provide contraceptive failure as a reason for a TOP request $(p=0.008)$. Money worries and contraceptive failure were highly ranked in all categories of education attainment.

The study population mirrored the local ethnic distribution. ${ }^{12}$ The women were mainly white British (93.4\%) and therefore it was deemed that there was not enough diversity to assess the effect of ethnicity. 
Table 2 Ranked reasons for a termination of pregnancy request

\begin{tabular}{|c|c|c|c|c|c|c|}
\hline \multirow[b]{2}{*}{ Reason } & \multirow{2}{*}{$\begin{array}{l}\text { Frequency } \\
\text { of reason }\end{array}$} & \multicolumn{3}{|c|}{ Ranking $[n(\%)]$} & \multirow{2}{*}{$\begin{array}{l}\text { Percentage } \\
\text { number of } \\
\text { reasons } \\
(n / 527)\end{array}$} & \multirow{2}{*}{$\begin{array}{l}\text { Percentage } \\
\text { number of } \\
\text { women } \\
(n / 274)\end{array}$} \\
\hline & & 1st & 2nd & $3 r d$ & & \\
\hline Money worries & 111 & $52(19.0)$ & $45(16.4)$ & $14 \quad(5.1)$ & 21.0 & 40.5 \\
\hline Contraceptive failure & 108 & $41(15.0)$ & $48(17.5)$ & $19(6.9)$ & 20.5 & 39.4 \\
\hline May affect education or career & 77 & $23(8.4)$ & $16 \quad(5.8)$ & $38(13.9)$ & 14.6 & 28.1 \\
\hline Family complete & 71 & $40(14.6)$ & $20(7.3)$ & $11(4.0)$ & 13.4 & 25.9 \\
\hline Not in relationship/unmarried & 61 & $46(16.8)$ & $8 \quad(2.9)$ & $7 \quad(2.5)$ & 11.5 & 22.3 \\
\hline Unstable relationship & 37 & $22(8.0)$ & $11(4.0)$ & $4(1.5)$ & 7.0 & 13.5 \\
\hline $\begin{array}{l}\text { Do not think partner is a suitable } \\
\text { father }\end{array}$ & 17 & $7 \quad(2.5)$ & $5(1.8)$ & $5 \quad(1.8)$ & 3.0 & 6.2 \\
\hline Never wanted children & 16 & $8(2.9)$ & $3(1.1)$ & $5(1.8)$ & 3.0 & 5.8 \\
\hline Unsatisfactory relationship & 11 & $4(1.5)$ & $4(1.5)$ & $3(1.1)$ & 2.0 & 4.0 \\
\hline Violent relationship & 10 & $7 \quad(2.5)$ & $1(0.4)$ & $2(0.7)$ & 2.0 & 3.6 \\
\hline Others & 8 & $7 \quad(2.5)$ & $1(0.4)$ & $0 \quad(0.0)$ & 1.5 & 2.9 \\
\hline No reason provided & - & $17(6.2)$ & - & - & & \\
\hline Total & 527 & & & & 100.0 & \\
\hline
\end{tabular}

Contraceptive failure as a reason for a TOP request is different to the other reasons. It may be a reason for an unintended pregnancy but may not reflect why the woman does not want to be pregnant in the first place. One hundred and eight women offered contraceptive failure as a reason for their request. It was, however, the only reason reported by 16 women. The other reasons most commonly associated with contraceptive failure were 'money worries' and 'may affect education or career'.

\section{DISCUSSION}

Abortion is both a social and a medical issue and it is linked closely to the prevailing societal conditions of a particular country or culture. While many studies have examined the reasons given by women for undergoing a TOP, very few of these studies were conducted in the UK. ${ }^{2}{ }^{413}$ Our study therefore adds a significant contribution to the UK literature on the subject.
The reasons provided for TOP are intricately complex and difficult to express for many women. Often the reasons are inter-related and connected. It remains a sensitive topic in the UK even with the legalisation of abortion in $1967 .^{14}$ This complexity surrounding TOP requests has previously been demonstrated in a number of studies. ${ }^{3} 49$ In our study, $6 \%$ of women did not provide any reasons for their request, and some women gave only one reason despite being encouraged to choose multiple reasons from a list of options. The reasons offered for a TOP request are now discussed in relation to the categories most commonly identified.

\section{Financial constraints}

The most common reason given for requesting a TOP was 'money worries'. This concurs with previous research that gives financial constraints as one of the main reasons for women seeking a TOP. ${ }^{8}$ A USA

Table 3 Reasons for termination of pregnancy request by age group

\begin{tabular}{|c|c|c|c|c|c|c|c|c|c|}
\hline \multirow{3}{*}{$\frac{\text { Reasons }}{\text { Money worries }}$} & \multicolumn{9}{|c|}{ Age group (years) $[n(\%)]$} \\
\hline & \multicolumn{2}{|c|}{$\leq 21$} & \multicolumn{2}{|c|}{$22-29$} & \multicolumn{2}{|c|}{$>30$} & \multicolumn{2}{|c|}{ Unknown } & \multirow{2}{*}{$\begin{array}{l}\text { Total } \\
111\end{array}$} \\
\hline & 42 & $(25.6)$ & 48 & $(25.4)$ & 18 & $(12.5)$ & 3 & $(10.0)$ & \\
\hline Contraceptive failure & 28 & $(17.1)$ & 44 & $(23.3)$ & 26 & $(18.1)$ & 10 & (33.3) & 108 \\
\hline May affect education or career & 43 & $(26.2)$ & 18 & (9.5) & 12 & (8.3) & 4 & $(13.3)$ & 77 \\
\hline Family complete & 10 & (6.1) & 20 & $(10.6)$ & 35 & $(24.3)$ & 6 & $(20.0)$ & 71 \\
\hline Not in a relationship/unmarried & 21 & $(12.8)$ & 20 & $(10.6)$ & 18 & $(12.5)$ & 2 & (6.7) & 61 \\
\hline Unstable relationship & 6 & (3.7) & 15 & (7.9) & 15 & $(10.4)$ & 1 & $(33.3)$ & 37 \\
\hline Do not think partner is a suitable father & 6 & (3.7) & 7 & (3.7) & 4 & $(2.7)$ & 0 & $(0.0)$ & 17 \\
\hline Never wanted children & 5 & (3.0) & 4 & (2.1) & 6 & $(4.2)$ & 1 & $(33.3)$ & 16 \\
\hline Unsatisfactory relationship & 3 & $(1.8)$ & 5 & (2.6) & 3 & (2.1) & 0 & $(0.0)$ & 11 \\
\hline Violent relationship & 0 & $(0.0)$ & 5 & $(2.6)$ & 4 & $(2.8)$ & 1 & $(33.3)$ & 10 \\
\hline Others & 0 & $(0.0)$ & 3 & (1.6) & 3 & (2.1) & 2 & $(6.7)$ & 8 \\
\hline Total & 164 & & 189 & & 144 & & 30 & & 527 \\
\hline
\end{tabular}


Table 4 Reasons for termination of pregnancy request by marital status

\begin{tabular}{|c|c|c|c|c|c|}
\hline \multirow{3}{*}{$\frac{\text { Reason }}{\text { Money worries }}$} & \multicolumn{5}{|c|}{ Marital status $[n(\%)]$} \\
\hline & Single & Married & Divorced & Unknown & \multirow{2}{*}{$\begin{array}{l}\text { Total } \\
111\end{array}$} \\
\hline & $69(21.0)$ & $30(12.8)$ & $8(16.3)$ & $4 \quad(26.7)$ & \\
\hline Contraceptive failure & $57(17.4)$ & $38(16.2)$ & $9(18.3)$ & $4 \quad(26.7)$ & 108 \\
\hline May affect education or career & $55(16.8)$ & $14 \quad(6.0)$ & $6(12.2)$ & $2 \quad(13.3)$ & 77 \\
\hline Family complete & $30 \quad(9.1)$ & $30(12.8)$ & $10(20.4)$ & $(6.7)$ & 71 \\
\hline Not in a relationship/unmarried & $52(15.9)$ & $3(1.3)$ & $5(10.2)$ & $(6.7)$ & 61 \\
\hline Unstable relationship & $22 \quad(6.7)$ & $5 \quad(2.1)$ & $8(16.3)$ & $2 \quad(13.3)$ & 37 \\
\hline Do not think partner is a suitable father & $13 \quad(4.0)$ & $3(1.3)$ & $1 \quad(2.0)$ & $(0.0)$ & 17 \\
\hline Never wanted children & $8 \quad(2.4)$ & $7 \quad(3.0)$ & $1 \quad(2.0)$ & $(0.0)$ & 16 \\
\hline Unsatisfactory relationship & $9 \quad(2.7)$ & $0 \quad(0.0)$ & $1 \quad(2.0)$ & $(6.7)$ & 11 \\
\hline Violent relationship & $9 \quad(2.7)$ & $1 \quad(0.4)$ & $0 \quad(0.0)$ & $(0.0)$ & 10 \\
\hline Others & $4(12.2)$ & $4 \quad(1.7)$ & $\begin{array}{ll}0 & (0.0)\end{array}$ & $(0.0)$ & 8 \\
\hline Total & 328 & 135 & 49 & 15 & 527 \\
\hline
\end{tabular}

study suggested that a TOP was linked to disruptive events in a woman's life including poverty, unemployment of the woman or that of her partner, lack of housing, and numerous others. ${ }^{9}$

We believe that the challenges of the global financial climate are reflected in the choices advanced by our study participants.

The catchment area for the clinic covers a large area considered relatively socially deprived and a smaller neighbouring area of affluence. ${ }^{15}$ This study did not, however, specifically look at reasons for a TOP request based on deprivation indices such as income and employment.

\section{Contraceptive failure}

Contraceptive failure was included in the questionnaire because it is often given by women as a reason for a TOP request. ${ }^{2-4}$ This reason suggests that these pregnancies were unintended, but it is also probable that it reflects the fact that this is a socially acceptable answer even when no contraception was used. In this study, 15\% (16/108) of those who listed 'contraceptive failure' gave this as the only reason for their TOP request. We are aware that there is often another underlying reason why a woman does not wish to be pregnant; hence contraceptive failure is dissimilar to other primary reasons and may in itself not totally portray the respondent's full circumstances. The most commonly associated reasons with contraceptive failure were 'money worries' and 'may affect education or career'.

Contraceptive failure was given as one of the main reasons in all age groups. This strongly suggests to us that there is a disconnect between women and the use of effective contraception. A UK Parliamentary Advisory Group on contraception found that in UK local authorities where access to contraceptive services was restricted, there was a higher abortion rate than the national average. ${ }^{16}$ Other research has shown that a significant number of women are unaware of the

Table 5 Reasons for termination of pregnancy by educational status

\begin{tabular}{|c|c|c|c|c|c|c|c|c|c|}
\hline \multirow{3}{*}{$\frac{\text { Reason }}{\text { Money worries }}$} & \multicolumn{9}{|c|}{ Educational status [n (\%)] } \\
\hline & \multicolumn{2}{|c|}{$\overline{\text { GCSE }}$} & \multicolumn{2}{|c|}{ A-level } & \multicolumn{2}{|c|}{ Degree } & \multicolumn{2}{|c|}{ Unknown } & \multirow{2}{*}{\begin{tabular}{|l|} 
Total \\
111
\end{tabular}} \\
\hline & 48 & $(21.3)$ & 24 & $(26.1)$ & 31 & $(21.4)$ & 8 & $(12.3)$ & \\
\hline Contraceptive failure & 36 & $(16.0)$ & 22 & $(23.9)$ & 34 & $(23.4)$ & 16 & $(24.6)$ & 108 \\
\hline May affect education or career & 33 & $(14.7)$ & 14 & $(15.2)$ & 26 & $(17.9)$ & 4 & $(6.2)$ & 77 \\
\hline Family complete & 31 & $(13.8)$ & 11 & $(12.0)$ & 16 & $(11.0)$ & 13 & $(20.0)$ & 71 \\
\hline Not in a relationship/unmarried & 28 & $(12.4)$ & 9 & (9.8) & 15 & $(10.3)$ & 9 & $(13.8)$ & 61 \\
\hline Unstable relationship & 16 & (7.1) & 3 & (3.3) & 11 & (7.6) & 7 & $(10.8)$ & 37 \\
\hline Do not think partner is a suitable father & 5 & $(2.2)$ & 3 & (3.3) & 4 & $(2.8)$ & 5 & (7.7) & 17 \\
\hline Never wanted children & 10 & $(4.4)$ & 4 & $(4.3)$ & 2 & (1.4) & 0 & $(0.0)$ & 16 \\
\hline Unsatisfactory relationship & 5 & $(2.2)$ & 1 & $(1.2)$ & 3 & $(2.1)$ & 2 & (3.1) & 11 \\
\hline Violent relationship & 9 & $(4.0)$ & 0 & $(0.0)$ & 0 & $(0.0)$ & 1 & $(1.5)$ & 10 \\
\hline Others & 4 & $(1.8)$ & 1 & $(1.2)$ & 3 & $(2.1)$ & 0 & $(0.0)$ & 8 \\
\hline Total & 225 & & 92 & & 145 & & 65 & & 527 \\
\hline
\end{tabular}

GCSE, General Certificate of Secondary Education. 
full range of contraceptive options available to them, or that they misunderstand how to use their chosen method correctly. ${ }^{13}$ Our study found that women with higher educational attainment were more likely to provide contraceptive failure as a reason for a TOP request $(p=0.008)$. The reason for this finding is unclear to us.

\section{Potential interruption of education or career}

The selection of this reason implies 'wrong timing' for this pregnancy and that it was unintended. Not surprisingly, this featured as one of the foremost reasons for a TOP request in women aged 21 years and under who may well just be starting out on a career path or concluding a higher education qualification that could lead to better career prospects.

Although potential interruption of education or career was offered as the primary reason for a TOP request, this implies a lack of effective use of contraception resulting in an unplanned pregnancy. This agrees with the findings of other studies that show large numbers of young women engaging in sexual intercourse without using contraception with adverse health, social and economic outcomes. ${ }^{17} 18$ Provision of age-appropriate sex education may potentially have a positive impact on teenage pregnancy rates. ${ }^{19}$

\section{Completion of family}

For women aged 30 years and older, our study found that the principal reason for a TOP request was that women felt their family was complete. This agrees with other research that finds older women who are still sexually active and fecund but who have achieved their desired family size are at risk of unintended pregnancy and abortion. ${ }^{20}$

Unsurprisingly, divorced or separated women also gave family completion as the foremost reason for a TOP request. A variety of reasons for this finding included relationship issues, messy or ongoing divorce proceedings, the anticipated difficulty with a oneparent family, possible lack of financial or emotional support from the estranged partner, timing, ${ }^{9}{ }^{21}$ and perceived stigmatisation from peers.

\section{Study strengths}

Our study is one of a limited number that explore the reasons for a TOP request for women in the UK. The study population covers a wide geographical area since our facility provides the only TOP service in two English counties. The findings of the study provide us with insight into the relationship between sociodemographic factors and TOP in the UK.

\section{Study limitations}

This was a quantitative study with scripted answers. This design may have had an impact on the quality of the responses obtained as deeper nuances may have been lost. Excluding women who did not speak
English may have introduced selection bias as the study population region is a favoured destination of migrants from continental Europe, some of whom do not speak English.

A convenience sampling method was used to recruit participants but an invitation to participate in the study was not extended to all women visiting the clinics. There was a significant reduction in recruitment rate on days when clinics were perceived to be busy or when members of the research team were not present during clinics. We believe our findings to be compelling but that caution should be exercised in extrapolating the results to the general population due to the relatively low numbers of study participants. Reliable data on the number of women approached and or excluded were not recorded.

\section{CONCLUSIONS}

The main reasons given for TOP requests include financial constraints, contraceptive failure, completion of family, and interruption of education or career. These reasons are intricately interwoven. Knowledge and understanding about the reasons for a TOP empowers stakeholders to have informed debates and focused discussions around policymaking, service planning and care delivery. Unplanned pregnancies carry great emotional and financial cost to some women and to society. Greater understanding of the reasons for TOP requests allows commissioners and clinicians to proffer targeted solutions in an increasingly cost-conscious health economy.

Access to contraception remains a challenge, especially in socially deprived regions covering wide geographical areas. Utilising the limited resources available, health care systems need to evolve to ensure that the best contraceptive advice is provided and that women are adequately supported in their contraceptive choices. Concerted efforts should also be made to improve access to contraception for women across all age groups. Our findings indicate that focused qualitative research on this subject is required to engender a better understanding that may impact significantly on policy and service provision.

Acknowledgements The authors would like to thank Gill Barnett for assistance with inputting data into the spreadsheet and Nkechi Emenike for editorial assistance.

\section{Competing interests None.}

Ethics approval National Research Ethics Service (NRES) Committee Yorkshire and the Yorkshire and Humber - Sheffield NRES (REC reference number 10/H1308/42).

Provenance and peer review Not commissioned; externally peer reviewed.

\section{REFERENCES}

1 Department of Health. Abortion Statistics, England and Wales: 2012. 2012. https://www.gov.uk/government/uploads/system/ 
uploads/attachment_data/file/211790/2012_Abortion_Statistics. pdf [accessed 27 July 2013].

2 Bankole H, Sing S, Haas T. Reasons why women have induced abortions: evidence from 27 countries. Int Fam Plan Perspect 1998;24:117-127,152.

3 Finer LB, Frohwirth LF, Dauphinee LA, et al. Reasons U.S. women have abortions: quantitative and qualitative perspectives. Perspect Sex Reprod Health 2005;37:110-118.

4 Kirkman M, Rowe H, Hardiman A, et al. Reasons women give for abortion: a review of the literature. Arch Womens Ment Health 2009;12:365-378.

5 Biggs MA, Gould H, Foster DG. Understanding why women seek abortions in the US. BMC Womens Health 2013;13:29.

6 Norton J. Teenage pregnancy and abortion. Practice Nurse 2010;39:43-49. Academic Search Premier, Ipswich, MA. [accessed 27 July 2013].

7 Blanc AK, Wolff B, Gage AJ, et al. Negotiating Reproductive Outcomes in Uganda. Makerere, Uganda: Macro International and Institute of Statistics and Applied Economics (ISAE), Makerere University, 1995.

8 Jones RK, Darroch JE, Henshaw SK. Patterns in socioeconomic characteristics of women obtaining abortions in 2000-2001. Perspect Sex Reprod Health 2002;34:226-235.

9 Jones RK, Frohwirth L, Moore AM. More than poverty: disruptive events among women having abortions in the USA. J Fam Plann Reprod Health Care 2012;39:36-43.

10 Mitchell EMH, Halpern CT, Kamathi EM, et al. Social scripts and stark realities: Kenyan adolescents' abortion discourse. Cult Health Sex 2006;8:515-528.

11 John R, Johnson JK, Kukreja S, et al. Domestic violence: prevalence and association with gynaecological symptoms. BJOG 2004;111:1128-1132.
12 Hull City Council. Population. http://www.hullcc.gov.uk/portal/ page?_pageid $=221,147225 \&$ \&dad $=$ portal\&_schema $=$ PORTAL [accessed 15 April 2013].

13 Bury L, Ngo TD. "The Condom Broke!” Why do Women in the UK have Unintended Pregnancies? London, UK: Marie Stopes International, 2009.

14 The National Archives. Abortion Act 1967. http://www. legislation.gov.uk/ukpga/1967/87/section/7 [accessed 29 July 2013].

15 Hull City Council. Deprivation. http://www.hullcc.gov.uk/ portal/page?_pageid $=221,196604 \& \_$dad $=$portal $\&$ _ schema $=$ PORTAL [accessed 29 July 2013.].

16 All-Party Parliamentary Group on Sexual and Reproductive Health in the UK. Healthy Women, Healthy Lives? The Cost of Curbing Access to Contraception Services. http://www.fpa.org. uk/sites/default/files/healthy-women-healthy-lives-full-reportjuly-2012.pdf [accessed 29 July 2013].

17 Paranjothy S, Broughton H, Adappa R, et al. Teenage pregnancy: who suffers? Arch Dis Child 2009;94:239-245.

18 Fullerton D, Dickson R, Eastwood AJ, et al. Preventing unintended teenage pregnancies and reducing their adverse effects. Qual Health Care 1997;6:102-108.

19 Mauldon J, Luker K. The effects of contraceptive education on method use at first intercourse'. Fam Plann Perspect 1996;28:19-24.

20 Sedgh G, Bankole A, Singh S, et al. Legal abortion levels and trends by woman's age at termination. Int Perspect Sex Reprod Health 2012;38:143-153.

21 Larsson M, Aneblom G, Odlind V, et al. Reasons for pregnancy termination, contraceptive habits and contraceptive failure among Swedish women requesting an early pregnancy termination. Acta Obstet Gynecol Scand 2002;81:64-71.

\section{ANNE SZAREWSKI JOURNAL MEMORIAL AWARD WINNER 2015}

The inaugural Anne Szarewski Journal Memorial Award has been won by $\mathrm{Dr}$ Laura Percy for her article entitled 'Would an exclusively contraceptive clinic help meet the needs of patients attending an integrated sexual health service?'.

In addition to her article being published in a future issue of the Journal of Family Planning and Reproductive Health Care, the winner also has the opportunity to present her work at an FSRH conference within the next 12 months, and will receive complimentary registration for that conference.

Entries for the Anne Szarewski Journal Memorial Award must be submitted no later than 31 March annually. See this issue of the Journal or the FSRH website (http://www.fsrh.org/pages/scholarships_and_awards.asp) for further details. 